\title{
Mechanical Properties of High Strength Concrete Containing Coal Bottom Ash and Oil-Palm Boiler Clinker as Fine Aggregates
}

\author{
Mahmood Soofinajafi ${ }^{1, a}$, Payam Shafigh², Farid Wajdi Akashah ${ }^{3}$, Hilmi Bin Mahmud ${ }^{1}$ \\ ${ }^{1}$ Department of Civil Engineering, Faculty of Engineering, University of Malaya, 50603, Kuala Lumpur, Malaysia. \\ ${ }^{2}$ Department of Building Surveying, Faculty of Built Environment, University of Malaya, 50603, Kuala Lumpur, Malaysia. \\ ${ }^{3}$ Centre for Construction, Building \& Urban Studies (CeBUS), Faculty of Built Environment, University of Malaya, 50603, Kuala Lumpur, \\ Malaysia.
}

\begin{abstract}
This research aims to utilize Coal Furnace Bottom ash (CBA) and Oil-Palm Boiler Clinker (OPBC) as fine aggregate in concrete mix proportions. They are solid wastes from power plant and Oil Palm industry, respectively. Since these by-products do not have any primary use and are pure waste, an opportunity to use them as aggregate in concrete industry not only is economical but also will be an environmental friendly opportunity leading towards a more sustainable production chain. CBA and OPBC sands had similar grading to normal sand but have lower density and higher water absorption. In a high strength concrete, normal sand was replaced up to $25 \%$ with either CBA or OPBC. Test results showed that although water absorption of these wastes was more than normal sand but the slump value of concrete containing each of these wastes showed that these concretes had good workability. All mixes containing these wastes had slightly lower compressive strength at early ages and equivalent or higher compressive strength at later ages compared to control mix. The 28-day compressive strength of these concretes was in the range of 69-76 MPa which can be categorized as high strength concrete. In general, the performance of OPBC was better than $\mathrm{CBA}$ at $25 \%$ replacement level. However, it is recommended that at least $12.5 \%$ of total volume of fine aggregate in a high strength concrete is used of $\mathrm{CBA}$ or OPBC.
\end{abstract}

Keywords: Coal Bottom Ash, Oil-Palm Boiler Clinker, Fine Aggregate, Compressive Strength, High Strength Concrete

$\begin{array}{ll}\begin{array}{ll}\text { Nomenclatures } \\ \text { MPa }\end{array} & \text { Mega Pascal, Concrete compressive strength, } \\ & \text { N/mm }{ }^{2} \\ \text { w/b } & \text { Water to binder ratio } \\ \text { w/c } & \text { Water to cement ratio } \\ & \\ \text { Abbreviations } \\ \text { ASTM } & \text { American Society for Testing and Materials } \\ \text { OPBC } & \text { Oil-Palm Boiler Clinker } \\ \text { OPBCC } & \text { Oil-Palm Boiler Clinker Concrete } \\ \text { CBA } & \text { Coal Bottom Ash } \\ \text { CBAC } & \text { Coal Bottom Ash Concrete } \\ \text { HSC } & \text { High Strength Concrete } \\ \text { OPC } & \text { Ordinary Portland Cement } \\ \text { ACI } & \text { American Concrete Institute } \\ \text { FA } & \text { Fly Ash } \\ \text { OPS } & \text { Oil-Palm Shell } \\ \text { GHG } & \text { Green-House Gases } \\ \text { LWA } & \text { Light Weight Aggregate } \\ \text { LWAC } & \text { Light Weight Aggregate Concrete } \\ \end{array}$

\section{Introduction}

Concrete as a major constructional material makes a significant contribution to the triple bottom lines environmental, social and economic - of sustainable development. In many sectors throughout the years, concrete has enabled the reduction of $\mathrm{CO} 2$ emissions and other negative environmental impacts. As of year 2006, $7.5 \mathrm{~km} 2$ of concrete is made each year. This amount is more than $1 \mathrm{~m} 2$ for every person on earth [1]. Fundamental concrete is generally analysed and designed with respect to its three core constituent parts, binder, aggregate and water [2]. This paper adopts the view of Troxell [3] when it comes to definition of satisfactory concrete. Workability, defined by BS 102 [4] is a topic that comes always hands in hands with $\mathrm{w} / \mathrm{c}$. W/c has direct relation with workability and reverse relation with strength. In other words, low w/c leads to high strength but low workability and high w/c leads to high workability and low strength [5].

Reason such as the enormity of the volume of constituent materials used from earth resources to produce the yearly need of concrete in construction and the large quantities of $\mathrm{CO} 2$ emissions created during the

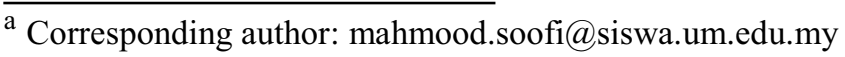


production, have given concrete a not necessarily environmental friendly general appearance. The environmental footprint left by concrete around the world does not seem to be compatible with the demands of sustainable development [6].

By introducing the constituent materials replacement concept producing concrete can be a sustainable and environmental friendly process. Using these recyclable materials as Pozzolan constituent materials or even aggregates in concrete production can actually be called an upcycling process. The earlier term can be justified knowing that many of the mentioned byproducts do not have any primary usage and are pure waste and using them in concrete production is actually making them valuable [7].

Both Fly Ash (FA) and Coal Bottom Ash (CBA) are also used as replacements for fine aggregates in concrete mix design. Although similar to natural fine aggregate, bottom ash is lighter and more brittle and has a greater resemblance to cement clinker. Its lighter nature and high water absorption found by research studies makes it a good replacement in high strength or light weight concrete [8]. Throughout the work that has been conducted it has not only been replaced for fine aggregate but also used as a replacement for cement. Due to its chemical carbonated nature containing $\mathrm{CO} 2$ with adding the right admixtures it can gain the paste glue state to work as a cementitious material [9].

Past researches on $\mathrm{CBA}$ showed that, the high porosity of CBA is a sign of causes the $w / c$ of the concrete to not be able to be taken as exact. The amount of internally absorbed water by CBA is released to the concrete over time, being part of the production process with the concrete still in the fresh state. The presence of bottom ash increased the quantity of water loss by bleeding, the bleeding time and also the water release rate, and the higher the bottom ash content of the concrete the greater this effect [10].

The chemical composition of the bottom ash is given in Table 1. As according to the table, calcium content of CBA is lower than $1 \%$. According to the total amount of $\mathrm{SiO} 2, \mathrm{~A} 2 \mathrm{O} 3$ and $\mathrm{Fe} 2 \mathrm{O} 3$ together that is $88.5 \%$ of the CBA, the ash belongs to ASTM Type F ash [11]. For this CBA, the loss on ignition (LOI) is mainly due to carbon which amount of carbon was found to be $3.8 \%$, which gives $13.9 \% \mathrm{CO} 2$, while the measured quantity of $\mathrm{CO} 2$ was $14 \%$. The remaining LOI $(0.8 \%)$ is certainly due to combined water in residual clay [12].

Malaysia is one of the greatest producers and exporters of palm oil products all over the world. A large amount of by-product wastes is collected throughout the palm oil processing phases. One of those would be Oil-Palm Boiler Clinker (OPBC), which is gathered in large portions during the oil palm shell (OPS) and fibre incineration process. In recent years, OPBC is disposed of by landfill which not only causes soil pollution but also affects the ground water supply source. Hence, the consumption of these abundantly available wasted byproducts in the construction industry will not only help to reduce the environmental problems but also provide an alternative to the diminishing natural aggregates [13]. Previous studies in 2002 and 2008 have shown that
$\mathrm{OPBC}$ can be used as coarse lightweight aggregate in concrete and that the density and the 28-day compressive strength of concrete containing this aggregate both fulfil the requirements of structural light weight aggregate concrete (LWAC) [14,15,23].

Table 1. Oxides (wt \%)

\begin{tabular}{ccccc}
\hline $\mathrm{SiO}_{2}$ & $\mathrm{Al}_{2} \mathrm{O}_{3}$ & $\mathrm{Fe}_{2} \mathrm{O}_{3}$ & $\mathrm{MgO}$ & $\mathrm{CaO}$ \\
\hline 56.0 & 26.7 & 5.8 & 0.6 & 0.8 \\
\hline & & & & \\
\hline $\mathrm{Na}_{2} \mathrm{O}$ & $\mathrm{K}_{2} \mathrm{O}$ & $\mathrm{TiO}_{2}$ & $\mathrm{~S}$ & $\mathbf{L O I}$ \\
\hline 0.2 & 2.6 & 1.3 & 0.1 & 4.6 \\
\hline
\end{tabular}

OPBC is mainly used as fine aggregate due to the fact that it is easy to crush. There are case in which it has even been used in powder form for making a composite artificial aggregate. It was observed that after crushing the clinker, much of the crushed aggregate is fine aggregate. Hence, due to the availability, OPBC was used as fine aggregate. Secondly, OPBC is a lightweight aggregate. If it can be used successfully as fine aggregate in concrete, the density of concrete will be reduced [16].

Previous studies on concrete constituent material replacement show that the replacement of various types of recycled or by-product materials as aggregates had made a noticeable progress all around the world to decrease the dependency on and use of virgin earth aggregates in production of concrete [6]. This research aims to further develop the diversity of knowledge on these replacement materials by undertaking a comparative study between two relatively less wellknown materials (OPBC and $\mathrm{CBA}$ ) and the traditionally used typical constituent concrete material (in the case of this project, mining sand).

The purpose of this study is to underline the feasibility of using both 'Coal Bottom Ash' (CBA) and 'Oil-Palm Boiler Clinker' (OPBC) in comparison, as two upcyclable waste by-product, in the concrete mix.

The objectives are:

1. To check fundamental material properties of CBA and OPBC in comparison to ordinary sand to see the possibility of their replacement in concrete to achieve comparable properties of concrete from strength and safety point of view.

2. To produce $60 \mathrm{MPa}$ HSC using CBA and OPBC having workability of higher than $180 \mathrm{~mm}$,

3. To determine mechanical properties of HSC using partial replacement of sand by $12.5 \%$ and $25 \%$ of each CBA and OPBC in separate mixes,

4. To compare mechanical properties of $\mathrm{CBA}$ concrete with OPBC concrete and concrete containing ordinary sand.

\section{EXPERIMENTAL PROGRAM}

\subsection{General Research Experiment Design}


This research is based on experimental works and data comparison. The main concentration of the work is in line with research objective to develop relationship between the amount percentage of the CBA and OPBC as upcycled materials used in the designed mixes and the characteristics of the produced concretes. A regular mix design with typical post curing characteristics was used as the control mix. While the amount of recycled material used in mixes would be the variables, the constant values will be portions of every other element included in those mixes excluding the fine aggregate. Each material was included in the comparative mixes only by replacement and not to addition. Initial material testing were taken place to develop comparable characteristics only for OPBC and CBA as which their variations contribute to the project results. The achieved results were not only used in final cause and effect discussions but also served as foundation data next to available literature review for designing trial and final mix designs. After trial mixes and designing final mixes the next stage was casting and curing. In this stage a schedule for casting was designed and according to nature of the chosen to be carried on tests.

Specific gravity, water absorption, and bulk density are the characteristics which have been chosen to be investigated for $\mathrm{CBA}$ and OPBC. Mix designs were designed consisting a total of 5 mixes of high strength concrete casted using increasing percentages of sand replacement proportions of both OPBC and CBA. The next stage was to determine the properties of concrete in both fresh and hardened stages. Concrete parameters chosen to be investigated in this report are compressive stress and tensile stress.

\subsection{Experiment Materials}

\subsubsection{Coarse Aggregate}

The coarse aggregate used in this work for all the mix designs is crushed granite aggregate. Maximum size of $20 \mathrm{~mm}$, angular shape and a rough surface texture can be mentioned as the main characteristics of this aggregate that is complied with MS29 [15]. The coarse aggregate was air dried fully in open space outdoors under the sun and sieved before used in mixing. It has the specific gravity of $2.66 \mathrm{~kg} / \mathrm{m} 3$ and water absorption of $0.57 \%$.

\subsubsection{Fine Aggregate}

The typical sand used in the study as fine aggregate was mining sand having the size of $150 \mu \mathrm{m}$ to $5 \mathrm{~mm}$. The mining sand used during this project has the typical properties of $0.94 \%$ water absorption, specific gravity of $2.5 \mathrm{~kg} / \mathrm{m} 3$ according to MS30:Part2 [17]. The fine aggregate was air dried in open space to reach SSD (Saturated Surface Dry) condition to maintain the moisture loss of the wet mixture due to water absorption of sand.

The sieve analysis test was done in accordance to ASTM C136 [18] showed the chosen sand is to be categorized in zone 1 as classified in BS 882: Part 103

[19]. The fineness modulus for this sand is 2.70 .

\subsubsection{CBA and OPBC}

Both CBA and OPBC used for the project are made in Malaysia. They were delivered directly from burner mills factory sites to the research. Both materials were treated similar to fine sand as to be fine aggregate replacements. They were clean washed with tap water and air dried in open space to reach SSD (Saturated Surface Dry) condition then kept in control conditions until the casting process.

\subsubsection{Ordinary Portland Cement (OPC)}

In all mix designs OPC was used as the main binder as known as the most popular and typical type of cement used in concrete where there is no exposure to sulphates. It is produced by Tasek Corporation Berhad. known as type 1 Portland Cement and conforms to MS 522, Part 1 [20]. The basic characteristics of this cement are surface area of $335 \mathrm{~m} 2 / \mathrm{kg}$, average particle size of $10 \mu \mathrm{m}$ and specific gravity of $3.10 \mathrm{~kg} / \mathrm{m} 3$.

\subsubsection{Superplasticizer (SP)}

The super plasticizer used in this study was Sika ViscoCrete-2199. It is a modified polycarboxylate ether based superplasticizers as mentioned in product specifications having a specific gravity of $1.20 \mathrm{~kg} / \mathrm{m} 3$. The product has a thick liquid state and comes in brown colour. The Sika catalogue mentioned that ViscoCrete2199 is a highly effective liquid superplasticizer for the production of free flowing concrete or as a substantial water-reducing agent for promoting high ultimate and early strengths" [21].

\subsubsection{Water}

A water quality which is filtered and clarified in other words potable, is efficient enough to use for mixes in accordance to BS 8110 [19]. In this project the laboratory tap water that is the Malaysian household and domestic pipe water; was used to create the concrete mix.

\subsection{Universal Stress Testing Machine}

The universal stress testing machine is a machine used to conduct the strength and stress tests for variety of mechanical properties of concrete such as compression, tensile and flexure strengths. The machine has different modes and sections for each test. The machine used for this test is made by ELE International Limited, a British company, with the serial number of 974-01-0105 and a $2500 \mathrm{kN}$ load frame.

\subsection{Concrete Production}

\subsubsection{Trial Mix}


A trial mix set was designed, according to the findings from literature review, to investigate three potential mixes to find the ultimate control mix for this project to satisfy the requirements of the project objective. Fly ash is used as a present component in control mix and all the other mixes including the trial mixes. After the data from this procedure was obtained, the best fit mix for control mix was designed and the rest of comparative mixes were designed. The mix proportions of each mix design is showed in Table 2.

Table 2. Trial Mix Design

\begin{tabular}{l|ccc}
\hline Mix No. & $\mathbf{1}$ & $\mathbf{2}$ & $\mathbf{3}$ \\
\hline Cement & 500 & 480 & 450 \\
Fly Ash & 50 & 70 & 50 \\
Super plasticizer & 5.5 & 5.5 & 5.5 \\
Binder (Cement + & 550 & 550 & 550 \\
Fly Ash + SP) & 1 & 1 & 1 \\
SP to binder ratio \% & 192 & 187 & 170 \\
Water & 0.35 & 0.34 & 0.31 \\
Water to binder & 960 & 973 & 870 \\
ratio (w/b) & 640 & 677 & 800 \\
\hline Fine aggregate & & & \\
\hline
\end{tabular}

\subsubsection{Mix Design}

The mix designs were finalized in accordance to the trial mix and the material properties obtained by experiments beforehand using absolute volume method. The method has been clearly defined in "Standard Practice for Selecting Proportions for Normal Weight Concrete". Absolute volume method is a rather accurate method in which parameters such as the specific gravity of the constituting materials will be used to calculate the absolute volume each ingredient will be occupying in a unit volume of concrete in accordance to American Concrete Institute, Committee 211: standard practice for proportioning of concrete mixes [22].

For this research the replacement method was used due to the fact that by reducing the use of cement, more economical and environmental friendly mixes can be produced that is an advantage in line with environmental friendly objectives of this research.

After all considerations it was decided that the research of effect of replacement sand with $\mathrm{CBA}$ and OPBC will be better investigated if all the other characteristics including the binder portion were kept constant. The replacement amount was decided to be tested in $0,12.5$ and 25 percent for both CBA and OPBC. Having these percentage replacements, 5 mix designs were sufficient for the project. The 5 mixes, their codes and constituent proportions are tabulated below in Table 3 .

Table 3. Mix Design

\begin{tabular}{lccccc}
\hline & $\mathbf{0 \%}$ & $\mathbf{1 2 . 5 \%}$ & $\mathbf{1 2 . 5 \%}$ & $\mathbf{2 5 \%}$ & $\mathbf{2 5 \%}$ \\
Mix Name & Control & CBA & OPBC & CBA & OPBC \\
Mix Code & $\mathrm{mx} 1$ & $\mathrm{mx} 2$ & $\mathrm{mx} 3$ & $\mathrm{mx} 4$ & $\mathrm{mx} 5$ \\
\hline
\end{tabular}

\begin{tabular}{lcccccc}
\hline Cement & $\mathrm{Kg}$ & 51.70 & 51.70 & 51.70 & 51.70 & 51.70 \\
$\begin{array}{l}\text { Super } \\
\text { Plasticizer }\end{array}$ & $\mathrm{g}$ & 570 & 570 & 570 & 570 & 570 \\
Fly Ash & $\mathrm{Kg}$ & 5.70 & 5.70 & 5.70 & 5.70 & 5.70 \\
Water & $\mathrm{Kg}$ & 18.40 & 18.40 & 18.40 & 18.40 & 18.40 \\
Granite & $\mathrm{Kg}$ & 100.00 & 100.00 & 100.00 & 100.00 & 100.00 \\
$\begin{array}{l}\text { Sand } \\
\text { Bottom }\end{array}$ & $\mathrm{Kg}$ & 94.00 & 82.25 & 82.25 & 70.50 & 70.50 \\
ash Sand & $\mathrm{Kg}$ & 0 & 11.75 & 0 & 23.50 & 0 \\
$\begin{array}{l}\text { Clinker } \\
\text { Sand }\end{array}$ & $\mathrm{Kg}$ & 0 & 0 & 11.75 & 0 & 23.50 \\
$\begin{array}{l}\text { Extra } \\
\text { Water }\end{array}$ & $\mathbf{K g}$ & 0 & 3.00 & 1.50 & 5.00 & 3.00 \\
Total & $\mathrm{Kg}$ & 18.40 & 21.40 & 19.90 & 23.40 & 21.40 \\
Water & $\mathrm{NA}$ & 0.321 & 0.373 & 0.347 & 0.408 & 0.373 \\
W/C & & & & & & \\
\hline
\end{tabular}

Mx1 and $\mathrm{mx} 2$ contained $12.5 \%$ sand replacement of $\mathrm{CBA}$ and OPBC respectively while $\mathrm{mx} 3$ and $\mathrm{mx} 4$ contained $25 \%$ sand replacement of CBA and OPBC respectively. As it is seen above the amount of water added to each mix is slightly different since the concentration during mix proportioning was not only to similarities in $\mathrm{w} / \mathrm{c}$ ration but also similarities in consistency of the slump test result of the fresh mix as different fine aggregates have different amount of water absorption.

\subsection{Fresh Concrete Slump Tests}

Table 4. Slump classes

\begin{tabular}{cc}
\hline Slump class & Slump $(\mathbf{m m})$ \\
\hline S1 & $10-40$ \\
S2 & $50-90$ \\
S3 & $100-150$ \\
S4 & $160-210$ \\
S5 & $\geq 220$ \\
\hline
\end{tabular}

As soon as the concrete is mixed and the desirable consistency using visual comparison by naked eye is reached before the concrete is poured into molds the slump test takes place. The test in this project was done based on BS 1881: 102. According to European Standard EN 206-1 (2000) five classes of slump have been designated, as tabulated in Table 4 above.

\section{Results and Discussion}

The experimental results obtained are divided into three groups as outlined in the subsections.

\subsection{Properties of the Targeted Constituent Materials (Mining Sand, OPBC, CBA)}

\subsubsection{Bulk Density Properties}


The density test results for CBA, OPBC and typical mining sand are shown in the Fig. 1. From the table it can be seen that CBA has the lowest both, loose and compacted density between all three materials. On the other hand typical sand is the densest while loose sand has the density of $1573 \mathrm{~kg} / \mathrm{m} 3$ that is $41 \%$ and $31 \%$ higher than CBA and OPBC respectively.

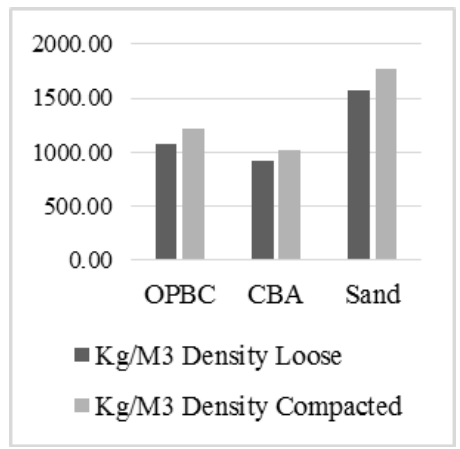

Fig. 1. Bulk Density

\subsubsection{Sieve Analysis Properties (Particle Size Distribution)}

As shown in Fig. 2 the particles spread quite evenly for all three materials hence they are all quite well graded. For both sand and OPBC $60 \%$ of material pass through the $1.18 \mathrm{~mm}$ sieve but for CBA the passing amount for the mentioned sieve is almost $74 \%$. In general sand and OPBC have very similar curves that is a sign of similar particle size distribution while CBA graph has a slightly gentler curve proofing of larger particle size.

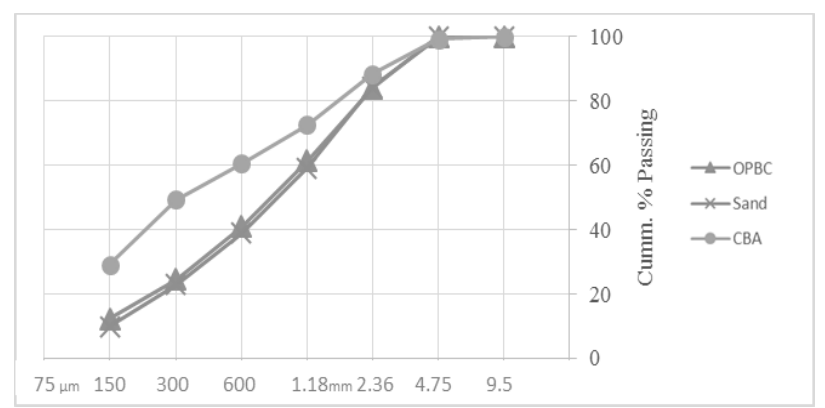

Fig. 2. sieve analysis

\subsubsection{Specific Gravity and Water Absorption Properties}

The saturated (apparent), saturated surface dry (SSD) and oven dry specific gravities of CBA, OPBC and mining sand are given in the Fig. 3 below. The oven-dry specific gravity shows that CBA is the lightest among all and sand the heaviest. Meanwhile according to the SSD results OPBC has the highest rate of water absorption. This happens due to the high amount of porosity that OPBC particles have. The higher water absorption may lead to loss of workability with time and reduce the water available in the mix for cement reaction. To overcome this problem all materials must be kept similarly not in dry conditions.

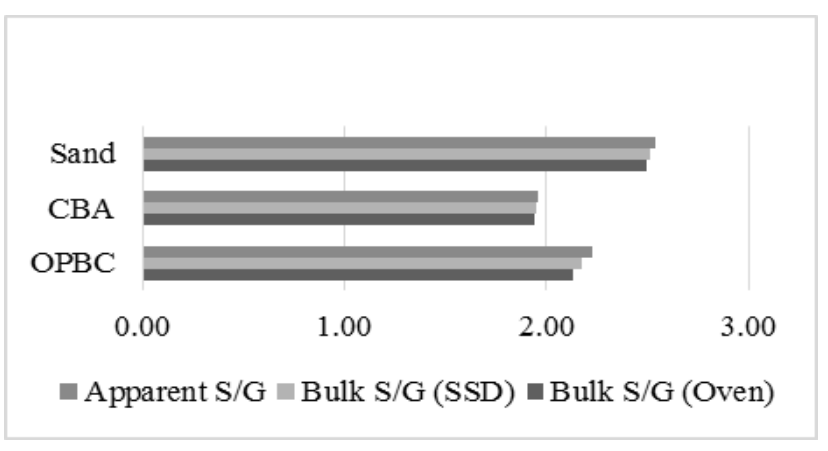

Fig. 3. Specifec gravity

\subsection{Slump Test Results (Workability)}

Table 5 contains parameters such as amount of water in the initial design to achieve expected slump consistency, the water to cement ratio (water to binder ratio) and mix code for each mix.

Table 5. Slump

\begin{tabular}{|c|c|c|c|c|c|c|}
\hline \multicolumn{2}{|c|}{ Mix Name } & $\stackrel{\varrho}{\varrho}$ & 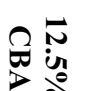 & $\stackrel{0}{\underline{n}}$ & $\overbrace{D}^{N}$ & $\varrho_{0}^{0}$ \\
\hline \multicolumn{2}{|c|}{ Mix Code } & E્己 & 趂 & E્己 & E्र & $\mathbb{Z}_{u}^{E}$ \\
\hline Slump & $\mathbf{m m}$ & 190 & 220 & 220 & 220 & 185 \\
\hline $\begin{array}{l}\text { Total } \\
\text { Water }\end{array}$ & Kg & 18.4 & 21.4 & 19.9 & 23.4 & 21.4 \\
\hline $\mathbf{w} / \mathbf{c}$ & NA & 0.321 & 0.373 & 0.347 & 0.408 & 0.373 \\
\hline
\end{tabular}

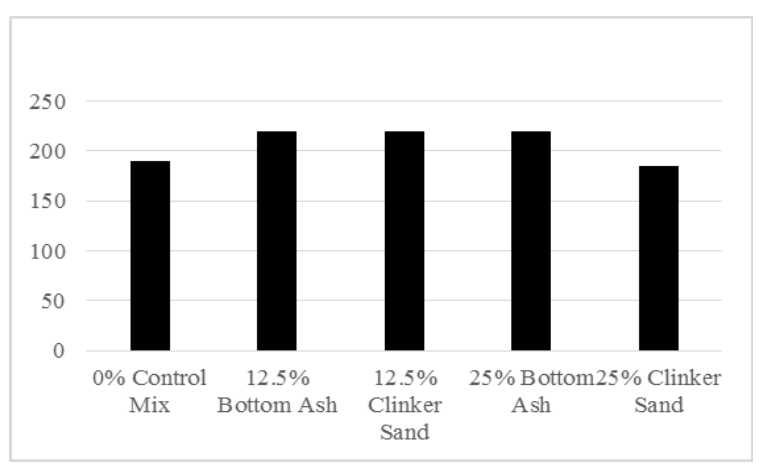

Fig. 4. Slump (mm)

As in general, the increase in slump value increases the workability in concrete. The slump can vary from zero to even $90 \%$ of the original height in very fluid mixes. Fig 4. Shows the slump results in comparison.

Superplasticizer (SP) was added to the mixes to $10 \%$ of weight of OPC. The amount was chosen $10 \%$ to be constant. The portion of SP added was kept constant for all mixes since the reason of addition was only to increase cohesiveness and not to effect workability. Although workability is heavily impacted by w/c ratio, binder content and SP; since the amount of binder was kept almost the same, the changes in slump can directly be connected to changes in different material used as fine aggregate and their characteristics such as water 
absorption. As it can be seen in the graph, all mixes have an acceptable medium workability of 185 to 220 slump. So in general the concrete will not lose much of its workability if the fine aggregate is partially replaced with CBA or OPBC.

\subsection{Properties of Hardened Concrete}

\subsubsection{Compressive Strength}

According to BS EN 12390: Part 3: compressive strength test specimens, Testing of hardened concrete (2002) the minimum compressive strength for concrete to be HSC is $55 \mathrm{MPa}$ by the age of 28 days from curing.

The 28-day cubical compressive strength targeted for this research is $60 \mathrm{MPa}$; that is in regards to the concrete fully cured in water. The average 28 -day compressive stresses acquired in experiment for water cured specimens for $12.5 \% \mathrm{CBA}, 12.5 \%$ OPBC, $25 \% \mathrm{CBA}$, $25 \%$ OPBC and control mix are 69.52, 75.83, 68.70, 71.85 and $66.69 \mathrm{MPa}$ respectively. Table 9 shows the average strength achieved in 1, 3, 7, 28 and 56 day ages for all mixes cured typically in water.

According to the Table 6 all mixes have achieve higher than $55 \mathrm{MPa}$ compressive strength at the age of 28 day. Their strength is even higher than $60 \mathrm{MPa}$. Hence all mixes fall under the HSC category and the targeted objective of the research is achieved. According to the Fig. 5 it can be observed that, general strength of concrete decreases for both $\mathrm{mx} 4$ and $\mathrm{mx} 5$ that contain $25 \%$ of material replacement. Furthermore $12.5 \%$ replacement seem to be closer to the optimum amount of the replacement in the case of both materials and High initial strength is achieved in $12.5 \%$ OPBC mix. In accordance to Fig. 5 a stable pace of strengthening can be seen in $12.5 \%$ CBA mix. $12.5 \%$ CBA has achieved the highest strength in 56 days and $12.5 \%$ OPBC has achieved the highest strength in 28 days.

Table 6. Compressive strength test results

\begin{tabular}{cccccc}
\hline & $\mathbf{0 \%}$ & $\begin{array}{c}\mathbf{1 2 . 5 \%} \\
\text { CBA }\end{array}$ & $\begin{array}{c}\mathbf{1 2 . 5 \%} \\
\text { OPBC }\end{array}$ & $\begin{array}{c}\mathbf{2 5 \%} \\
\text { CBA }\end{array}$ & $\begin{array}{c}\mathbf{2 5 \%} \\
\text { OPBC }\end{array}$ \\
\hline $\begin{array}{c}\text { Day } \\
\mathbf{1}\end{array}$ & 29.83 & 31.64 & 33.55 & 23.62 & 28.16 \\
Day & & & & & \\
$\mathbf{3}$ & 57.25 & 48.19 & 50.46 & 41.46 & 47.02 \\
Day & & & & & \\
$\mathbf{7}$ & 61.84 & 59.48 & 58.52 & 47.26 & 47.15 \\
$\begin{array}{c}\text { Day } \\
\mathbf{2 8}\end{array}$ & 66.69 & 69.52 & 75.83 & 68.70 & 71.85 \\
$\begin{array}{c}\text { Day } \\
\mathbf{5 6}\end{array}$ & 76.74 & 79.35 & 76.04 & 72.75 & 74.01 \\
\hline
\end{tabular}

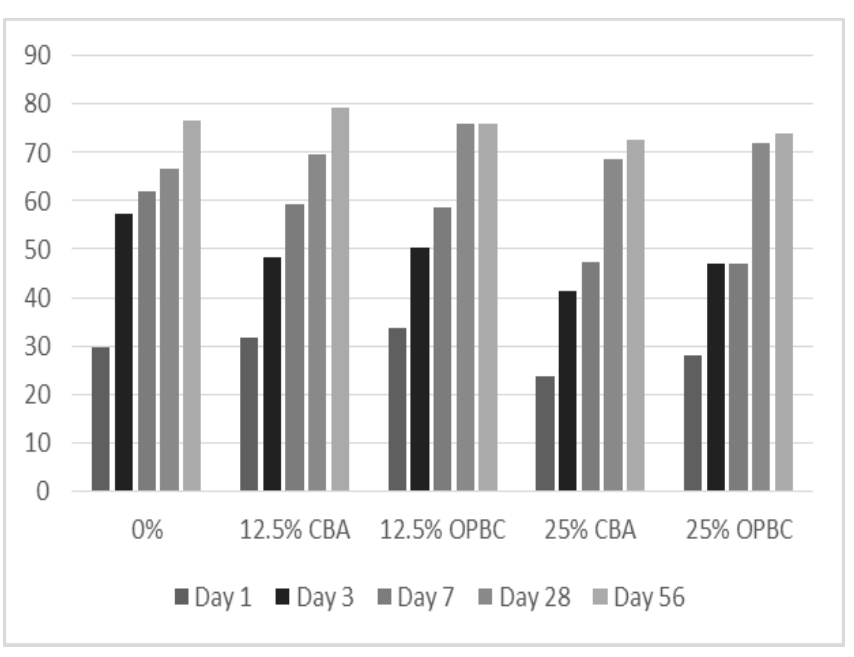

Fig. 5. Compressive strength test results categorized by mix composition

Fig. 5 also shows the compressive strength of all mixes categorized in mixes separately from the Day 1 after curing and Day 28th of curing. It can also be seen that in general CBA contained mixes have a higher early age strength comparing to other mixes and that can be caused by the low degree water absorption by CBA in early stages enough water is available for hydration. In other hand, OPBC mixes have highest final strength that might be a result of high porosity and water absorption of OPBC. Since the water is stored in pores and holes of OPBC particles it is only available for cement slowly and by time so the hydration process will take longer. In accordance to the figure, $12.5 \mathrm{OPBC}$ has the highest hardening acceleration rate since a $221 \%$ increase in its strength over 3 weeks can be seen that is more than triple of the initial strength.

\subsubsection{Splitting Tensile Strength}

As a very well-known concept, concrete's tensile strength is much less than its compressive strength. The results of splitting tensile will develop an understanding to the tensile ability of the research mixes.

Table 7 showed the splitting tensile test result for all mixes in different ages. It can be seen that $12.5 \%$ OPBC mix had the highest tensile strength at 28 days while control mix had took the title of having the highest tensile strength at 56 days. And the lowest strength belongs to 25 $\%$ OPBC at day 1 of curing. It is also visible that 12.5 OPBC mix has a stable increase all through its aging process and is showing desired results. The OPBC mixes had been maintaining a high level of tensile strength since day 1 .

Table 7 also shows that $12.5 \%$ replacement mixes for both materials had the smoothest growth gradient between all mixes. They gained strength slow and steady and show a desirable strength level. It can be seen that the control mix had the lowest tensile strengthening speed while having a high early age tensile strength. It could also be seen that in general OPBC had the highest speed of strength development for both mixes containing it. 
Table 7. Splitting tensile test results

\begin{tabular}{cccccc}
\hline & $\mathbf{0 \%}$ & $\begin{array}{c}\mathbf{1 2 . 5 \%} \\
\text { CBA }\end{array}$ & $\begin{array}{c}\mathbf{1 2 . 5 \%} \\
\text { OPBC }\end{array}$ & $\begin{array}{c}\mathbf{2 5 \%} \\
\text { CBA }\end{array}$ & $\begin{array}{c}\mathbf{2 5 \%} \\
\text { OPBC }\end{array}$ \\
\hline $\begin{array}{c}\text { Day } \\
\mathbf{1}\end{array}$ & 2.982 & 2.603 & 2.743 & 2.207 & 1.753 \\
Day & 4.165 & 3.633 & 3.984 & 4.193 & 4.089 \\
$\mathbf{7}$ & & & & & \\
day & 4.535 & 4.846 & 5.399 & 4.479 & 5.091 \\
$\mathbf{2 8}$ & & & & & \\
day & 6.124 & 5.696 & 5.804 & 4.656 & 5.270 \\
$\mathbf{5 6}$ & & & & & \\
\hline
\end{tabular}

\section{Conclusions}

Based on results obtained from 5 mixes the following conclusions can be made:

1. Based on the results obtain from test on properties of the targeted constituent materials, both OPBC and CBA have similar particle size distribution properties to mining sand which makes them more desirable replacement materials. Not to mention both OPBC and CBA have lower densities in comparison to sand which could be a beneficial advantage when it comes to production of light weight concrete.

2. The slump test results show an acceptable and practical degree of workability for all the mixes having slump of from $185 \mathrm{~mm}$ to $220 \mathrm{~mm}$ with $\mathrm{w} / \mathrm{c}$ ratio of 0.3 to 0.4. This means the percentage usage of SP was designed properly and suitable for mixes.

3. Compressive test results showed that in the age of 28 days all mixes have achieved strength higher than $60 \mathrm{MPa}$. Hence, the objective of research to produce HSC is achieved.

4. Compressive test results also show that in general $12.5 \%$ replacement mixes had higher and better results at 28 days in all tests comparing to $25 \%$ replacement mixes. Hence it seems like $12.5 \%$ is quite close to optimum level of replacement suitable for CBA and $\mathrm{OPBC}$.

5. From the results obtained from the splitting tensile test, it can be seen that the $25 \%$ replacement mixes have low early strength gain comparing to the three other mixes. That might be due to high amount of water absorption by the high percentage of replaced materials as both OPBC and CBA have relatively high water absorptions. It seems moisturizing these mixes will affect their final strength greatly. Anyway in 7 days' time after curing, both $25 \%$ mixes caught up with tensile strength of other mixes and control mix.

6. From the results obtained from the splitting tensile test, the sudden increase in strength from the 1st day to 7 th day for both $25 \%$ mixes indicates happening of a secondary reaction in the dry mix after initial hydration. The process seems to be a support to the hydration process. This can be due to reaction of OPBC or CBA with hydrated cement.
Finally, it was concluded that using the mentioned materials to extend of $12.5 \%$ as replacement is practical and economical.

Test results also show the comparability of OPBC and CBA concretes to OPC concrete using ordinary sand from mechanical properties point of view which creates the possibility of future research expansion in the field of concrete strength and safety.

\section{Acknowledgment}

Research reported in this publication was supported by the Ministry of Higher Education, Malaysia through the FRGS Grant (Grant No.: FP046-2014B).

\section{References}

1. Van Oss, H. G. (2013). Cement. US Geological Survey.

2. Shafigh, P.; Jumaat, M.Z.; and Mahmud, H. (2010). Mix design and mechanical properties of oil palm shell lightweight aggregate concrete: A review. International journal of the physical sciences, 5(14), 2127-2134.

3. Troxell, G., Raphael, J., \& Davis, R. (1958). Longtime creep and shrinkage tests of plain and reinforced concrete. Paper presented at the ASTM Proceedings.

4. British Standard. (1881). BS 1881: 102: Methods for determination of slump: BS.

5. Neville, A.M. (2008). Properties of Concrete, fourteenth ed. CTP-VVP, Malaysia.

6. Meyer, C. (2009). The greening of the concrete industry. Cement and Concrete Composites, 31(8), 601-605.

7. Mahmud, H. (1999). Engineering properties of fly ash concrete.

8. Manz, O. (1997). Worldwide production of coal ash and utilization in concrete and other products. Fuel, 76(8), 691-696.

9. Kim, H., \& Lee, H. (2011). Use of power plant bottom ash as fine and coarse aggregates in highstrength concrete. Construction and Building Materials, 25(2), 1115-1122.

10. Kanadasan, J., \& Razak, H. A. (2014). Mix design for self-compacting palm oil clinker concrete based on particle packing. Materials \& Design, 56, 9-19.

11. ASTM. (1958). C 125" Definition of Terms Relating to Concrete and Concrete Aggregates," 1958 Book of ASTM Standards. Part, 4, 588.

12. Khasreen, M. M., Banfill, P. F., \& Menzies, G. F. (2009). Life-cycle assessment and the environmental impact of buildings: a review. Sustainability, 1(3), 674-701.

13. Abdullahi, M., Al-Mattarneh, H., Hassan, A. A., Hassan, M., \& Mohammed, B. (2008). Trial mix design methodology for Palm Oil Clinker (POC) concrete.

14. Binti Robani, R., \& Chan, C. (2009). Reusing Soft Soils with Cement-Palm Oil Clinker (Poc) Stabilisation. Paper presented at the International 
Conference on Engineering and Education in the 21st Century.

15. MS29. (1995). Specification for coarse and fine aggregate in concrete MalaysiaStandard29: SIRIM, MS.

16. ASTM. (2014). Standard Test Method for Sand Equivalent Value of Soils and Fine Aggregate ASTM D2419 - 14.

17. MS30:Part2. (1995). Specification for Fine aggregates in concrete: SIRIM, MS.

18. ASTM Standard. (2006). C136-06, 2006," Standard Test Method for Sieve Analysis of Fine and Coarse Aggregates," ASTM International, West Conshohocken, PA.

19. British Standard. (1985). 8110: Part 1, Structural use of concrete-code of practice for design and construction. British Standards Institute, London UK, 3-8.

20. MS522. (2007). Compositions, specifications and conformity criteria for common cements, Malaysia Standard.

21. Sika. (2012). Superplasticizers. Water Reducers (High Range). From http://mys.sika.com/en/solutions_products/02/02a00 1/02a001sa03/02a001sa03100/02a001sa03109.html

22. ACI Committee. (1991). Standard Practice for Selecting Proportions for Normal, Heavyweight, and Mass Concrete (ACI 211.1-91). Paper presented at the American Concrete Institute.

23. Abdullahi, M., Al-Mattarneh, H., \& Mohammed, B. (2010). Characterisation of Palm Oil Clinker Aggregate. International Journal of Applied Engineering Research, 5(16). 